\title{
CORROSION RESISTANCE OF METALIZED LAYERS ON STEEL PARTS IN VENTILATION MILL
}

\author{
Bore V. Jegdic ${ }^{1 *}$, Bojana M. Radojković ${ }^{1}$, Biljana M. Bobićl ${ }^{1}$,Marija Krmar $^{2}$, \\ Slavica Ristić \\ ${ }^{1}$ Institute of chemistry, technology and metallurgy, Njegoševa 12, \\ University of Belgrade, Serbia \\ ${ }^{2}$ Institute of general and physical chemistry, \\ Studentskitrg 12-16, Belgrade, Serbia \\ ${ }^{3}$ Institute Gosa, MilanaRakića 35, Belgrade, Serbia
}

Received 20.02.2018

Accepted 08.06.2018

\begin{abstract}
Corrosion behavior of metalized layers, obtained by Plasma Transferred Arc (PTA) process and by High-Velocity Oxygen Fuel (HVOF) process with the purpose to improve the wear resistance of vital parts of ventilation mill in a thermal power plant, has been tested. The test is performed using three electrochemical techniques, in a solution containing chloride and sulfate ions. It is shown that the steel surface (base metal) dissolves uniformly, without pitting or other forms of local dissolution. Morphology of metalized layers surface indicates that dissolution is non-uniform, but it still can be considered as general corrosion. The corrosion rate of base metal and metalized layer obtained by PTA process is rather low, while the corrosion rate of the metalized layer obtained by HVOF process is much higher. Also, the difference in corrosion potentials between the base metal and the HVOF layer is pretty high but slightly less than maximum allowed difference (prescribed by the standard), to avoid excessive galvanic corrosion. The values of corrosion rate obtained by different electrochemical techniques are in excellent agreement.
\end{abstract}

Keywords: Corrosion; metalized layers; electrochemical methods.

\section{Introduction}

Wear of ventilation mill parts in power plants occurs when the mixture of coal powder and sand particles flows over the surface of these parts. Hot wrought low-alloyed structural steels are frequently used for manufacturing of ventilation mill parts. Corrosion characteristics of these steels have been considered before [1-5]. Numerical simulation of

*Corresponding author: Bore Jegdić, borejegdic@yahoo.com 
multiphase flow of coal powder and sand enabled to define geometry for essential parts of the ventilation mill. Parts of ventilation mill with new or modified geometry are more resistant to wear. Also, application of wear resistant coatings additionally extended the working life of ventilation mill parts. Results of numerical simulation, as well as deposition of wear resistant coatings by metalization and hardfacing technique, are discussed in detail in [6-9].

Due to condensation of moisture during the breaking of work in the ventilation mill, the active corrosive environment is formed on the metalized surfaces that can cause corrosion of materials. Such environment is formed due to the dissolution of gaseous compounds from surrounding working environment. $\mathrm{pH}$ value of this corrosive environment is often below 4 (moderately acid environment) [10,11]. Because of that, it is critical to determine the resistance of metallic layers and steel (base metal) to corrosion. In the above-mentioned conditions, corrosion takes place as uniform dissolution, i.e.,the thickness of the materials gradually decrease.

Corrosion resistance of metalized layers depends on their chemical composition and microstructure. The typical microstructure is formed during structure and phase transformations in metallization process [12].

Testing of corrosion can be done in two different ways: an examination of test samples in real working conditions using non-destructive techniques (ultra-sonic measurement, acoustic emission) or using electrochemical methods. Corrosion is an electrochemical process, and lots of electrochemical methods are used for studies of general, local, galvanic and stress corrosion cracking, etc.

Quantitative indicator of general corrosion is the corrosion rate. In a short time, the value of corrosion rate can be determined by electrochemical techniques. As a result of electrochemical measurements, the corrosion current density is obtained, which can be expressed as a corrosion rate [13].

In this paper, results of corrosion resistance testing of metalized layers and base metal (steel) using different electrochemical techniques are presented. The corrosion rate is determined by following electrochemical methods: linear polarization resistance (LPR), electrochemical impedance spectroscopy (EIS) and linear sweep voltammetry (LSV). The corrosion rate is determined in the test solution containing chlorides and sulfates, in moderately acid $(\mathrm{pH}=3)$ environment. This solution simulates the most severe exploitation conditions in thermal power plants and in an industrial atmosphere.

\section{Experimental}

\section{Material}

Metalized layers A and B were obtained by Plasma Transferred Arc (PTA) process and by High-Velocity Oxygen Fuel (HVOF) process.

Plasma transferred arc (PTA) process is an overlay welding process with deposits that are homogenous and fused to the substrate, forming a metallurgical bond. Plasma transferred arc makes use of a constricted arc and powdered alloy, which is carried from a feeder to the plasma torch in a stream of argon gas.

High-velocity oxygen fuel (HVOF) process is a thermal spray coating process used to improve or restore a component's surface properties or dimensions, thus extending equipment life by significantly increasing erosion and wear resistance, and corrosion 
protection. Molten or semi-molten materials are sprayed onto the surface by means of the high temperature, high-velocity gas stream, producing a dense spray coating.

The chemical composition of metalized layers (A and B) is shown in Table 1 while chemical composition of base metal (steel S355J2G3) is shown in Table 2.

Table 1. Filler materials and deposition process of metalized layers.

\begin{tabular}{lccc}
\hline Filler material & Composition & Process* & $\begin{array}{c}\text { Layer hardness, } \\
\text { HV30 }\end{array}$ \\
\hline PG6503, powder (A) & Ni-Cr-B-Si/ 60\% WC & PTA & 650 \\
55586C, powder (B) & Co-Cr-Fe-C-W/WC & HVOF & 700 \\
\hline
\end{tabular}

*PTA - plasma transferred arc process

HVOF - high-velocity oxygen fuel process

More information on the chemical composition of powders A and B can be found in the technical sheets for these products $[14,15]$.

In the PTA process argon with 5 vol.\% hydrogen was used as a shielding gas. The flow rate of the shielding gas was $15 \mathrm{dm}^{3} \mathrm{~min}^{-1}$. Argon with a flow rate of $2.6-2.8 \mathrm{dm}^{3}$ $\mathrm{min}^{-1}$ was used as the plasma gas. The distance of the nozzle from the base material was $7 \mathrm{~mm}$. The voltage was $25-28 \mathrm{~V}$, and the current intensity was 50-60 A.

In the HVOF process oxygen with a flow rate of $845 \mathrm{dm}^{3} \mathrm{~min}^{-1}$ and nitrogen with a flow rate of $9.9 \mathrm{dm}^{3}, \mathrm{~min}^{-1}$ were used as carrier gasses, while kerosene with a flow rate of $0.38 \mathrm{dm}^{3} \mathrm{~min}^{-1}$ was used as a fuel. The distance of the nozzle from the base material was $7 \mathrm{~mm}$.

Table 2. The chemical composition of steel S355J2G3 wt. (\%), according to EN 10025-2 [16].

\begin{tabular}{lccccc}
\hline Element & $\mathrm{C}$ & $\mathrm{Si}$ & $\mathrm{Mn}$ & $\mathrm{P}$ & $\mathrm{S}$ \\
\hline wt.\% & 0.22 & 0.55 & 1.60 & 0.035 & 0.035 \\
\hline
\end{tabular}

\section{Electrochemical techniques}

Linear polarization resistance technique $(L P R)$ is used to determine polarization resistance $R_{\mathrm{p}}$ of metal in the corrosive environment [17]. Value of $R_{\mathrm{p}}$ is inversely proportional to corrosion current density $j_{\text {corr }}$, and to corrosion rate $v_{\text {corr }}$. Metal (metallized layer or steel), which is in the corrosion environment, is polarized in a narrow range of potential $(E= \pm 20 \mathrm{mV})$ relative to corrosion potential $E_{\text {corr, }}$ starting from cathodic to the anodic region, and the corresponding current $j$ is recorded. The value of $R_{\mathrm{p}}$ is determined as the slope of the experimental $E$ - $j$ curve, at the corrosion potential $E_{\text {corr }}$. Corrosion current density and corrosion rate are calculated using the experimental value of $R_{\mathrm{p}}$.

Electrochemical impedance spectroscopy $(E I S)$ is also used to determine $R_{\mathrm{p}}$ value. The $R_{\mathrm{p}}$ value can be used to calculate corrosion current density $j_{\text {cor }}$, and corrosion rate $v_{\text {cor }}$. The alternating potential of small amplitude $( \pm 10 \mathrm{mV})$ is imposed on the working electrode (metalized layer or steel) in the test solution. The applied frequency $f$ range is from $100 \mathrm{kHz}$ to $0.01 \mathrm{~Hz}$. An appropriate response in the form of alternating current is recorded, and the impedance $\mathrm{Z}$ is calculated depending on the frequency [18]. The $R_{\mathrm{p}}$ value is calculated on the basis of electrochemical impedance at very high and very low 
frequencies. Using the $R_{\mathrm{p}}$ values corrosion current density $j_{\text {corr }}$ and corrosion rate $v_{\text {corr }}$ can be calculated.

Corrosion current density $j_{\text {corr }}$ is calculated using the Stern-Geary equation [19]:

$j_{\text {corr }}=\mathrm{B} / R_{\mathrm{p}}$

where B is a constant that depends on the values of anodic and cathodic Tafel slopes $b_{\mathrm{a}}$ and $b_{\mathrm{c}}$ :

$\mathrm{B}=b_{\mathrm{a}} b_{\mathrm{c}} / 2.3\left(b_{\mathrm{a}}+b_{\mathrm{c}}\right)$

For the tested system, i.e., for metalized layer or base metal (steel) in the test solution with $\mathrm{pH}=3$, the value of constant $\mathrm{B} \sim 16 \mathrm{mV}[20,21]$. Therefore, the corrosion current density is:

$j_{c o r r}=16 \mathrm{mV} / R_{p}$

Corrosion rate $v_{\text {corr }}\left(\mathrm{mm} \mathrm{year}^{-1}\right)$ can be calculated using the Faraday law, based on corrosion current density $j_{\text {corr }}\left(\mu \mathrm{A} \mathrm{cm} \mathrm{cm}^{-2}\right)$, in accordance with ASTM G102 [19].

Linear sweep voltammetry $(L S V)$ technique is used to obtain cathodic and anodic polarisation curves (Tafel diagrams) [13]. Metalized layer or steel is polarized in the potential range $E= \pm 0.250 \mathrm{~V}$ relative to $E_{\text {corr }}$ and corresponding current $j$ is recorded. The corrosion current density $j_{\text {corr }}$ is determined directly from the obtained diagram $E-\log j$ by extrapolation of linear parts of anodic and cathodic polarization curves to the corrosion potential $E_{\text {corr. }}$

Electrochemical tests are carried out using the potentiostat Bio-Logic SP-200, in the solution containing sulphates and chlorides $\left(0.1 \mathrm{~mol} \mathrm{dm}^{-3} \mathrm{Na}_{2} \mathrm{SO}_{4}+0.3 \mathrm{~mol} \mathrm{dm}^{-3}\right.$ $\mathrm{NaCl})$ with addition of $\mathrm{H}_{2} \mathrm{SO}_{4}$ to set required $\mathrm{pH}$ value $(\mathrm{pH}=3)$. The tests are performed at room temperature, in the presence of atmospheric oxygen. The chemical composition of the test solution simulates the industrial atmosphere, which contains sulfates and chlorides and has moderately low $\mathrm{pH}$ value.

The tests are carried out in an electrochemical cell with a saturated calomel electrode (SCE) as a reference electrode and a Pt mesh as an auxiliary electrode. The working electrode is the base metal or the metalized layer. Working electrode with a surface area of $1 \mathrm{~cm}^{2}$ is exposed to the test solution.

Before the test, the sample was wet ground with progressively finer abrasive $\mathrm{SiC}$ paper (up to 600 grit), washed with ethanol and air dried. Before the beginning of polarization measurements, the sample was held $1800 \mathrm{~s}$ at open circuit potential, to establish a stable corrosion potential $E_{\text {corr }}$ LPR experiments are carried out at $0.167 \mathrm{mV} \mathrm{s}^{-1}$ sweep rate, while LSV experiments are performed with $1 \mathrm{mV} \mathrm{s}^{-1}$ sweep rate.

\section{Results}

Determination of polarization resistance $R_{p}$ from experimental LPR diagrams

Polarization diagrams obtained by testing metalized layers $\mathrm{A}$ and $\mathrm{B}$ and base metal in the solution of $0.1 \mathrm{~mol} \mathrm{dm}^{-3} \mathrm{Na}_{2} \mathrm{SO}_{4}+0.3 \mathrm{~mol} \mathrm{dm}{ }^{-3} \mathrm{NaCl}(\mathrm{pH}=3)$ are shown in Fig. 1. 

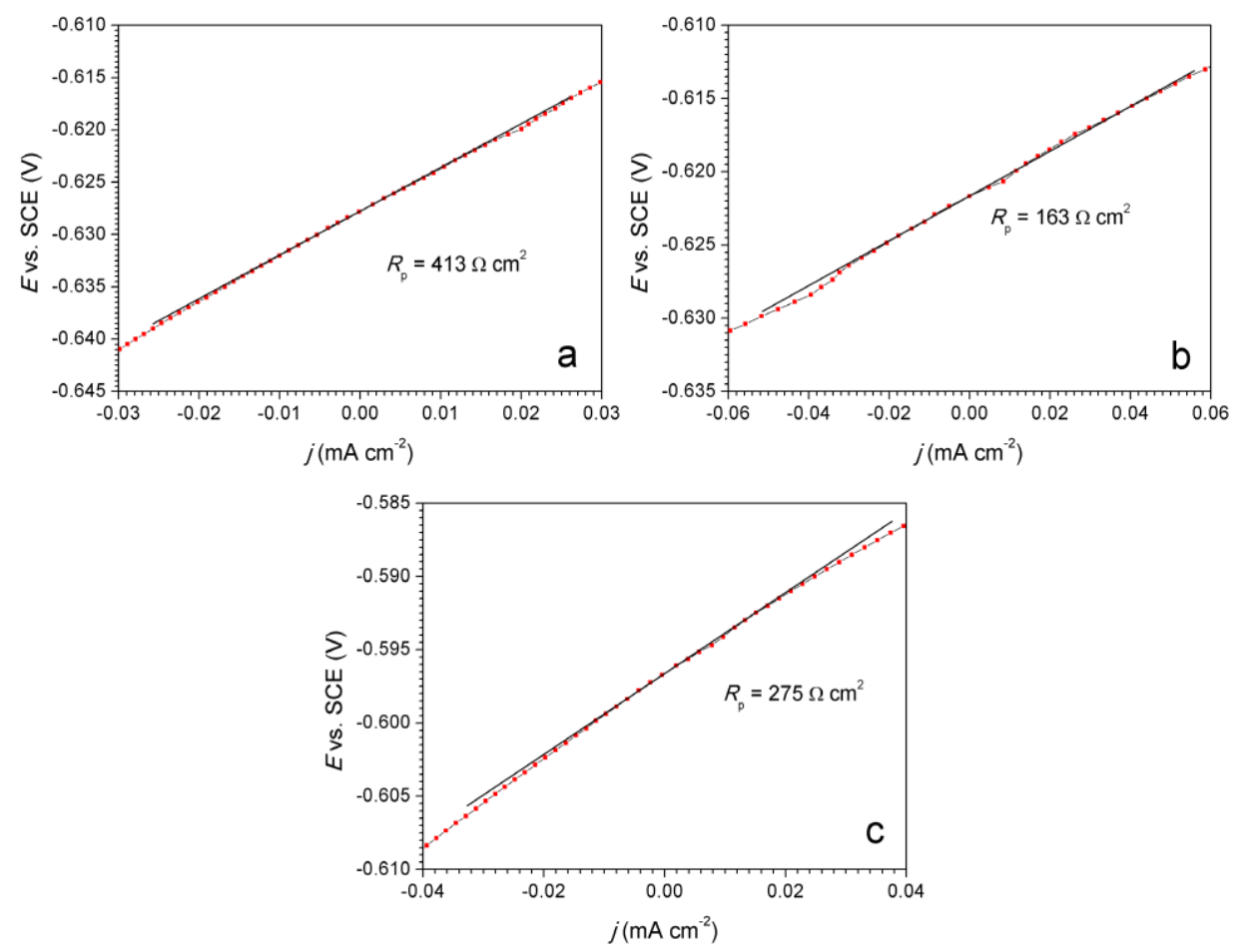

Fig. 1. Polarization diagrams obtained by LPR technique: a) metalized layer $A, b$ ) metalized layer $B$ and $c$ ) base metal.

Corrosion current density at corrosion potential $E_{\text {corr }}$ is $j=0$. Negative values of current density correspond to cathodic current density, while positive values correspond to anodic current density. The slope of the polarization curve $(\Delta E / \Delta j)$ at corrosion potential Ecorr corresponds to the value of polarization resistance $R_{\mathrm{p}}$. The value of corrosion current density and corrosion rate are inversely proportional to polarization resistance $R_{\mathrm{p}}$. The lower the polarization resistance is, the higher are corrosion current density and corrosion rate, and vice versa. The value of polarisation resistance for tested steel (base metal) in the test solution is $R_{\mathrm{p}}=275 \Omega \mathrm{cm}^{2}$ (Fig. 1c). The highest value of polarization resistance (the lowest corrosion rate) is obtained for the layer $\mathrm{A}\left(R_{\mathrm{p}}=413 \Omega\right.$ $\mathrm{cm}^{2}$, Fig. 1a). The lowest polarization resistance (the highest corrosion rate) is obtained for the layer B $\left(R_{\mathrm{p}}=163 \Omega \mathrm{cm}^{2}\right.$, Fig. $\left.1 \mathrm{~b}\right)$.

Corrosion current density $j_{\text {corr }}$ is calculated using equation 3 :

$$
\begin{aligned}
& j_{\text {corr }}=16 \mathrm{mV} / R_{\mathrm{p}}=16 \mathrm{mV} / 413 \Omega \mathrm{cm}^{2}=39 \mu \mathrm{Acm}^{-2} \text { (layer A) } \\
& j_{\text {corr }}=16 \mathrm{mV} / R_{\mathrm{p}}=16 \mathrm{mV} / 163 \Omega \mathrm{cm}^{2}=98 \mu \mathrm{A} \mathrm{cm}{ }^{-2}(\text { layer B) } \\
& j_{\text {corr }}=16 \mathrm{mV} / R_{\mathrm{p}}=16 \mathrm{mV} / 275 \Omega \mathrm{cm}^{2}=58 \mu \mathrm{Acm}^{-2} \text { (base metal) }
\end{aligned}
$$


Determination of polarization resistance $R_{p}$ from experimental EIS diagrams

Fig. 2a-c shows EIS diagrams (Nyquist plots). Nyquist diagrams show the real component of impedance $\left(Z_{\mathrm{Re}}\right)$ and imaginary component of impedance $\left(Z_{\mathrm{Im}}\right)$ in linear coordinates. It can be seen that the solution resistance is $R_{\mathrm{e}} \sim 30 \Omega \mathrm{cm}^{2}$ (left side of the diagram in Fig. 2a). On the right side of the same diagram is represented the total resistance $R_{\mathrm{e}}+R_{\mathrm{p}} \sim 440 \Omega \mathrm{cm}^{2}$. Accordingly, $R_{\mathrm{p}}=410 \Omega \mathrm{cm}^{2}$ (layer A). Calculated corrosion current densities are presented in Table 3.
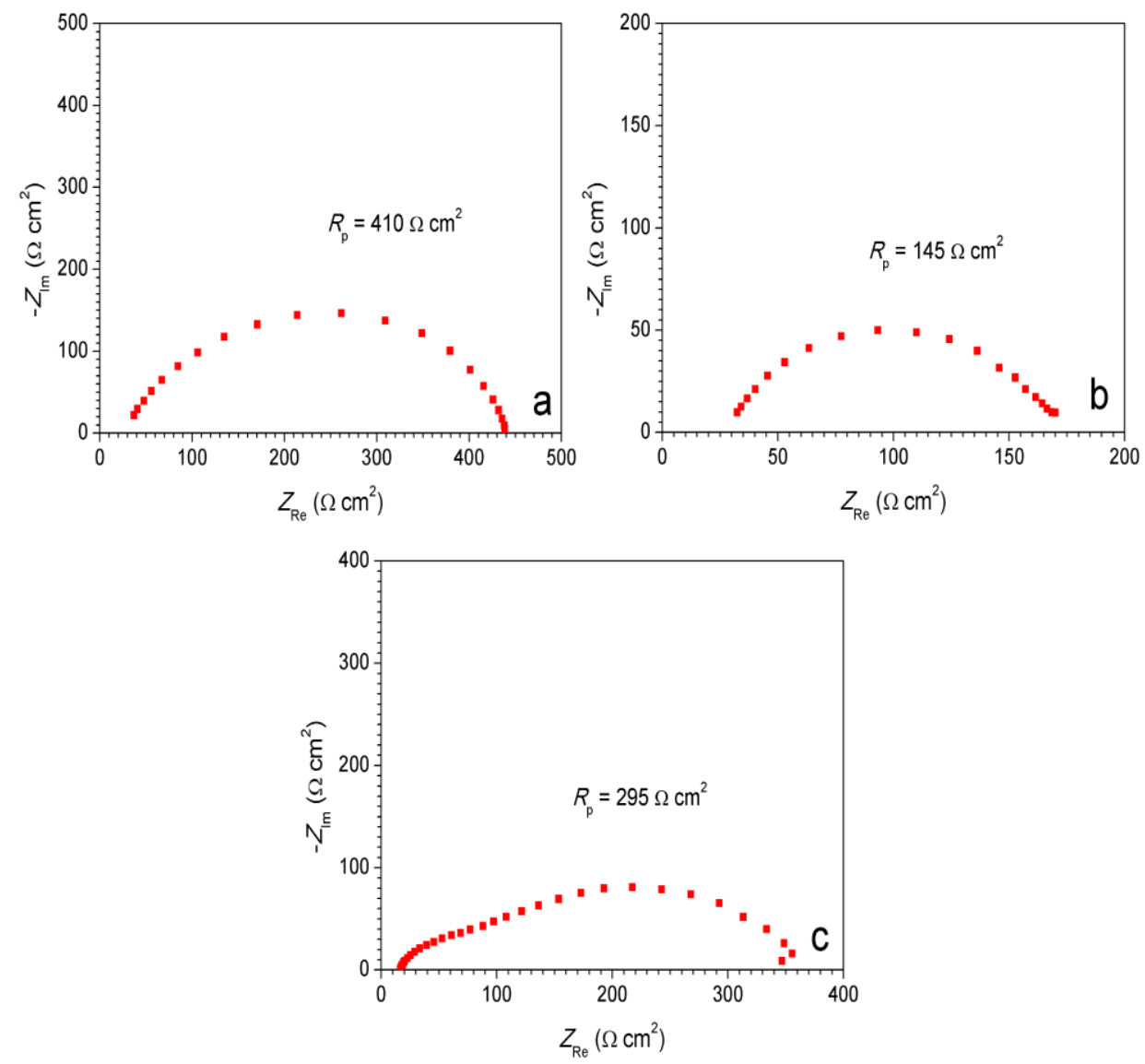

Fig. 2. Nyquist plots obtained by EIS technique: a) metalized layer A,

b) metalized layer $B$ and c) base metal.

\section{Estimation of corrosion current density from Tafel diagrams}

Tafel polarization diagrams obtained for metalized layers (A and B) and base metal are shown in Fig. 3a-c. 

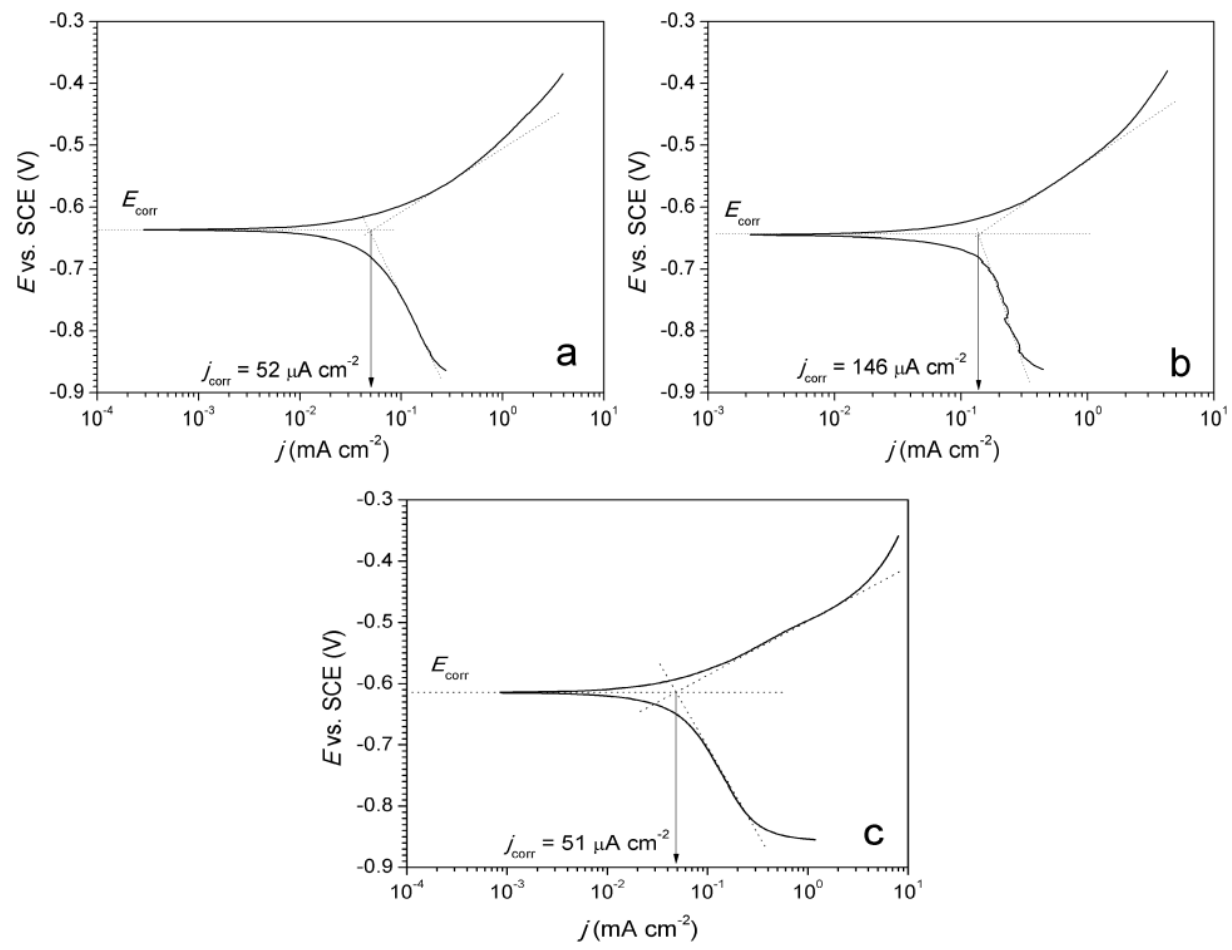

Fig. 3. Tafel diagrams obtained by LSV technique: a) metalized layer A, b) metalized layer $B$ and c) base metal.

Corrosion current density $j_{\text {corr }}$ is determined at the intersection of anodic and cathodic Tafel lines (at corrosion potential $E_{\text {corr }}$ ). For example, $j_{\text {corr }}=52 \mu \mathrm{A} \mathrm{cm}^{-2}$ for the layer A (Fig. 3a).

The quantitative results of the electrochemical tests are summarized in Table 3. In addition to $R_{\mathrm{p}}, j_{\text {corr }}$ values and $E_{\text {corr }}$ values (potential established on the sample surface before the corrosion test) are listed. The corrosion potential $E_{\text {corr }}$ is the thermodynamic indicator of the metal susceptibility to corrosion in the given corrosive environment. The more positive is the value of $E_{\text {corr }}$, the less is the thermodynamic driving force for the corrosion process to occur, and vice versa. As can be seen from Table 3, the base metal has the most positive $E_{\text {corr }}\left(E_{\text {corr }}=-614 \mathrm{mV}\right)$, while the layer B has the most negative $E_{\text {corr }}$ $\left(E_{\text {corr }}=-642 \mathrm{mV}\right)$. The difference between $E_{\text {corr }}$ values for the base metal and layer B is $28 \mathrm{mV}$, that is less than the standardized limiting value in order to avoid intensive galvanic corrosion in exploitation. For example, according to standard GOST 9.005 [22], the difference between corrosion potential values that are greater than $30 \mathrm{mV}$ (or $50 \mathrm{mV}$ ) is forbidden. 
Table 3. Results of electrochemical tests

\begin{tabular}{ccccccc}
\hline \multirow{2}{*}{ Sample } & $\begin{array}{c}E_{\text {corr }} \\
(\mathrm{mV})\end{array}$ & $\begin{array}{c}R_{\mathrm{p}} \\
\left(\Omega \mathrm{cm}^{2}\right)\end{array}$ & $\begin{array}{c}j_{\text {corr }} \\
\left(\mu \mathrm{A} \mathrm{cm}^{-2}\right)\end{array}$ & $\begin{array}{c}R_{\mathrm{p}} \\
\left(\Omega \mathrm{cm}^{2}\right)\end{array}$ & $\begin{array}{c}j_{\text {corr }} \\
\left(\mu \mathrm{A} \mathrm{cm}^{-2}\right)\end{array}$ & $\begin{array}{c}\text { Tafel } \\
j_{\text {corr }} \\
\left(\mu \mathrm{A} \mathrm{cm}^{-2}\right)\end{array}$ \\
\hline A & -638 & 413 & 39 & 410 & 39 & 52 \\
B & -642 & 163 & 98 & 145 & 110 & 146 \\
Base metal & -614 & 275 & 58 & 295 & 54 & 51 \\
\hline
\end{tabular}

It can be seen from Table 3 that values of corrosion current density obtained by LPR and EIS techniques are in excellent agreement. Corrosion current densities obtained by extrapolation of Tafel lines are slightly different. However, all electrochemical techniques show that the metalized layer B has the greatest corrosion rate. It can be recommended to use a filler material with a higher concentration of alloying elements, in order to shift $E_{\text {corr }}$ to more positive values. As a result, values of the corrosion current density and corrosion rate should be lower.

The application of LSV technique (Tafel diagrams) involves high anodic polarizations so that there is an intensive dissolution of the base metal surface and the surface of metalized layers (A and B) during the test. Dissolution of the metal surface is considerably less when using LPR or EIS technique. The appearance of the steel surface after electrochemical testing by LSV technique indicates that dissolution of the base metal is uniform, without pitting or other forms of local dissolution, which means that corrosion on the tested steel is general (uniform) corrosion in the applied test conditions. Dissolution of metalized layers A and B is somewhat less uniform. However, the surface morphology of these layers may also be considered as general corrosion.

\section{Conclusion}

The corrosion behavior of metalized layers obtained by Plasma Transferred Arc (PTA) process and by High-Velocity Oxygen Fuel (HVOF) process as well as of base metal (steel S355J2G3) in solution which contains chlorides and sulfates, has been tested. The chemical composition of this solution simulates the most severe exploitation conditions in thermal power plants and in an industrial atmosphere. It is shown that dissolution of the steel surface, in test conditions, is uniform, without pitting or other forms of local dissolution. Surface morphology of PTA and HVOF metalized layers is less uniform, but it still belongs to general (uniform) corrosion.

Three independent electrochemical techniques are used to determine values of corrosion current density and corrosion rate. It was shown that corrosion current densities of the base metal and PTA metalized layer are low, while corrosion current density of HVOF metalized layer is considerably higher. The difference between values of corrosion potential is the highest in the case of the base metal and HVOF metalized layer, but it is somewhat less than maximum allowed value according to standard (to avoid excessive galvanic corrosion). The use of filler metal with higher content of alloying elements can be recommended, in order to shift the value of corrosion potential to more positive values. This will result in lower values of corrosion current density and corrosion rate.

The quantitative values of corrosion rate indicators $\left(R_{\mathrm{p}}, j_{\text {corr }}\right)$ obtained by different electrochemical techniques are in excellent agreement. 


\section{Acknowledgment}

This work is co-financed by Ministry of Education, Science and Technological Development of the Republic of Serbia through projects TR 34028 and TR 35021.

\section{References}

[1] B. Kim, S. Kim, H. Kim: Adv Mater Sci Eng, 2018, (2018) Article ID 7638274, 13 pages.

[2] S. J. Oh, D. C. Cook, and H. E. Townsend: Corros Sci, 41 (1999) 1687-1702.

[3] Y. Hyun and H. Kim: Korean Journal of Metals and Materials, 54 (2016) 68-78.

[4] G. Su, X. Gao: Materials (Basel), 10 (2017) 938, 1-11.

[5] S. B. Lyon, Corrosion of Carbon and Low Alloy Steels, SHREIR'S CORROSION, Fourth Edition, Elsevier, Amsterdam, 2010, 1693-1736.

[6] M. Ristić, R. Prokić-Cvetković, M. Kozić, S. Ristić, B. Katavić: J Balk TribolAssoc, 21 (2015) 493-513.

[7] M. Kozić, S. Ristić, M. Puharić, B. Katavić, M. Prvulović: Sci-Tech Rev, 60 (2010) 39-47.

[8] M. Ristić, R. Prokić-Cvetković, B. Katavić, I. Vasović: Structural integrity and life, 15 (2015) 173-180.

[9] M. Kozić, S. Ristić, B. Katavic, B. Jegdić, M. Prvulović, M. Prokolab, S. Linić: Structural integrity and life, 17 (3) (2017) 221-228.

[10] Corrosion: Environments and industries, ASM Handbook, Vol 13C, S. D. Cramer, B. S. Covino Eds., ASM International, Ohio, 2006.

[11] P. R. Roberge, Corrosion engineering principles and practice, New York, 2008.

[12] J. R. Davis, Corrosion of Weldments, ASM International, Materials Park, Ohio, 2006.

[13] Corrosion test and standards: Application and interpretation, R. Baboian Ed., ASM International, Ohio, 2005.

[14] https://www.castolin.com/sites/default/files/product/downloads//6503-PTAPowder.pdf last access 25th May 2018

[15] https://www.castolin.com/sites/default/files/product/downloads//HVOF-powderCastoJet-55586C.pdf last access 25th May 2018.

[16] Hot rolled products of structural steels - Part 2: Technical delivery conditions for non-alloy structural steels-EN 10025-2.

[17] Standard test method for conducting potentiodynamic polarisation resistance measurements-ASTM G59.

[18] M. E. Orazem, B. Tribollet, Electrochemical impedance spectroscopy, Yon Wiley and Sons, New Jersey, 2008.

[19] Standard practice for calculation of corrosion rates and related information from electrochemical measurements-ASTM G102.

[20] Advances in corrosion science and technology, M.G. Fontana, R.W. Staehle Eds., Vol 6, Plenum Press, New York, London, 1976.

[21] NACE Corrosion Engineer's Reference Book, R. Baboian Ed., NACE International, Houston, Texas, 2002.

[22] Unified system of corrosion and ageing protection. Metals, alloys, metallic and nonmetallic coatings. Permissible and impermissible contacts with metals and nonmetals-GOST 9.005 . 


\section{(c) (i) CreativeCommonsLicense}

This work is licensed under a Creative Commons Attribution 4.0 International License. 